\title{
Uji performance turbin Savonius dengan penambahan konsentrator pada aliran air
}

\section{Test performance of the Savonius turbine by adding concentrators to the water flow}

\section{I.B. Alit*, I.M. Mara, I. G.B. Susana, S. Sapri}

Teknik Mesin Fakultas Teknik Universitas Mataram, Jln. Majapahit No. 62 Mataram Nusa Tenggara Barat Kode Pos : 83125, Telp. (0370) 636087; 636126; ext 128 Fax (0370) 636087. HP. 081999183088

*Email: alit.ib@unram.ac.id

\section{ARTICLE INFO \\ ABSTRACT}

Article History:

Received 17 September 2018

Accepted 4 December 2018

Available online 1 January 2019

\section{Keywords:}

Water energy

Savonius turbine

Concentrator

Coefficient performance

Efficiency system.

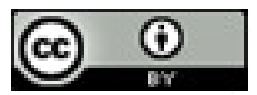

Utilization of water energy is essentially using potential energy and kinetic energy, kinetic energy flow of water which is a transformation of gravitational potential energy is used to drive turbines or waterwheels, Savonius turbine has a good Self Starting so it can rotate the rotor even though the fluid speed is low, the same thing the speed of the water flow has a low speed. The purpose of this research is to know the influence of the number of blades on rotation of rotor $(n)$, Torque $(T)$, Rotor power $(P)$, Coefficient of performance (CP), Efficiency system ( $n s)$, in this study the number of blades used are 2 blades, 3 blades and blades, the blades are then tested without the use of concentrator and by the addition of concentrator. The results of this study indicate that the turbine without concentrator or by using the addition of concentrator obtained the best performance on the number of blade 3 with average $\mathrm{CP}$ of 0.12 and 0.13 efficiency system of $9.83 \%$ and $11.75 \%$ then with the number of blades 2 with $C P$ averaging of 0.10 and 0.11 of efficiency system of $8.73 \%$ and $11.00 \%$ and the number of 4 blades with $C P$ averaged 0.06 and 0.07 and efficiency system of $3.91 \%$ and $4.76 \%$. Using the addition of concentrator may increase the performance of the turbine in water flow savonius seen from the increasing value of $C P$ and system efficiency at each number of blades tested.

Dinamika Teknik Mesin, Vol. 9, No. 1, Januari 2019, p. ISSN: 2088-088X, e. ISSN:2502-1729

\section{PENDAHULUAN}

Turbin Savonius merupakan salah satu jenis turbin angin poros vertikal. Turbin jenis ini memiliki banyak keuntungan dibandingkan jenis turbin lainnya, seperti: konstruksi sudu yang sederhana, biaya pembuatan murah, tidak dipengaruhi oleh orientasi arah angin, dan generator dapat ditempatkan di bawah menara. Turbin Savonius biasanya terdiri dari dua atau tiga buah sudu, jika dipandang dari atas akan tampak seperti huruf S, Ali (2013). 
Beberapa Penelitian telah dilakukan untuk meningkatkan performa turbin ini, seperti penelitian pengaruh jumlah blade, penggunaan penutup rotor, dan overlap ratio turbin Savonius terhadap performance. Jumlah sudu yang diteliri adalah 2,3 , dan 4 buah, sedangkan variasi overlap ratio 0,0 , $0,2,0,25,0,3$ dan 0,35. Hasilnya rotor Savonius 2 blade lebih efisien dibandingkan dengan 3 ataupun 4 blade, penggunaan penutup rotor menghasilkan efisiensi yang lebih besar daripada tanpa penutup rotor, rotor tanpa overlap ratio memiliki koefisien power yang lebih besar dibanding rotor dengan overlap ratio, Mahmoud dkk. (2012). Penelitian mengenai penggunaan turbin Savonius bertingkat dengan berbagai sudut juga telah diteliti, Alit dkk. (2016). Variasi sudut yang digunakan adalah $0^{\circ}$, $35^{\circ}, 45^{\circ}$, dan $90^{\circ}$. hasilnya sudut $0^{\circ}$, memiliki putaran rotor yang terbesar. Modifikasi turbin Savonius juga telah dirancang dan diuji untuk memperoeh unjuk kerjanya. Modifikasi meliputi pengaruh rasio overlap, blade shape factor, dan blade arc angle. Hasilnya rasio overlap 0.0, blade shape factor 0.5 , dan blade arc angle $110^{\circ}$ memiliki unjuk kerja yang terbaik, selanjutnya hasil modifikasi tersebut diuji di pantai Loang Baloq untuk pembangkit daya skala kecil, Alit dkk. (2018). Akhir-akhir ini penggunaan turbin Savonius telah banyak dikembangkan sebagai pembangkit enaga air, seperti penelitian yang dilakukan Golecha dkk. (2012). Turbin ini diuji pada aliran air dengan kecepatan rendah sekitar $0.45 \mathrm{~m} / \mathrm{s}$. Selanjutnya Purnama dkk. (2013) meneliti tentang rancang bangun turbin air menggunakan turbin Savonius pada aliran sungai dengan pemandu arah aliran. Hasilnya Turbin ini dapat berputar $20 \mathrm{rpm}$ pada kecepatan aliran 0,30 m/s. Dengan penambahan pengarah aliran terjadi peningkatan menjadi $33 \mathrm{rpm}$.

Selain memanfaatkan air jatuh,energi air atau (hydropower) dapat diperoleh dari aliran air datar. Dalam hal ini energi yang tersedia merupakan energi kinetik berdasarkan persamaan:

$$
E k=\frac{1}{2} m v^{2}
$$

Energi kinetik $(E k)$, adalah aliran air datar yang mengalir (Joule) dengan $m$ adalah massa fluida yang ditimbang $(\mathrm{kg})$ dengan $v$ adalah kecepatan aliran air $(\mathrm{m} / \mathrm{s})$ yang diukur menggunakan water current meter. Daya yang tersedia dinyatakan sebagai berikut (Balineni dkk., 2011):

Pair $=\frac{1}{2} \rho A v^{3}$

Daya air (Pair) yang diperoleh adalah dari potensi aliran air yang mengalir (watt) dengan $A$ sebagai luas daerah sapuan rotor $\left(\mathrm{m}^{2}\right)$. Luas daerah sapuan untuk turbin Savonius dapat dihitung dari dimensi rotor sebagai berikut:

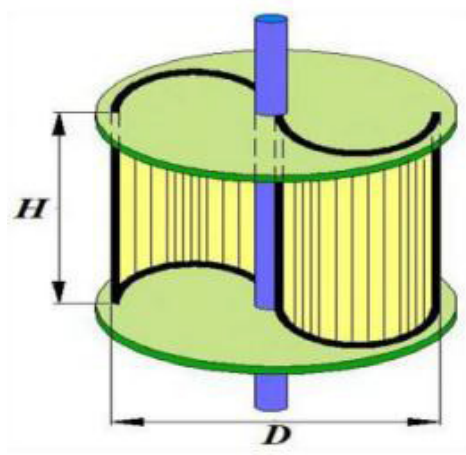

Gambar 1 Skematik rotor Savonius

$$
A=H D
$$

$A$ adalah luasan daerah sapuan rotor $\left(\mathrm{m}^{2}\right)$ dengan $H$ adalah ketinggian dari sudu turbin $(\mathrm{m})$ dan $D$ adalah diameter dari turbin (m). 


$$
P_{\text {rotor }}=T \omega=T \frac{2 \pi n}{60}
$$

Daya rotor $\left(P_{\text {rotor }}\right)$ adalah daya dari rotor yang diukur setelah mengalami pembebanan lampu, dengan Torsi $(\mathrm{N})$ dapat dihitung menggunakan beban pengereman, dimana $\omega$ kecepatan sudut (rad/s) dan $n$ adalah putaran poros rotor (rpm) yang diukur menggunakan tachometer pada poros turbin.

Koefisien performance (CP) ialah perbandingan antara daya yang dihasilkan oleh rotor dengan daya air, Persamaan koefisien daya sebagai berikut :

$$
C P=\frac{P_{\text {rotor }}}{\text { Pair }}
$$

$D$ adalah diameter dari rotor yang digunakan $(\mathrm{m})$ dan $\mathrm{n}$ putaran pada rotor yang diukur menggunakan tachometer (rpm) dimana $v$ adalah kecepatan aliran air $(\mathrm{m} / \mathrm{s})$ yang diukur menggunakan water current meter

Dengan mengukur besarnya tegangan dan arus yang dihasilkan, dapat diketahui besarnya daya listrik. Daya listrik dapat dihitung dengan menggunakan rumus :

$$
P l=V I
$$

Pl adalah daya listrik (watt) yang diperoleh dari tegangan dengan arus dimana $V$ adalah tegangan yang diperoleh dari generator yang diukur menggunakan volt ampere meter I Arus (ampere) adalah muatan Coulumb yang mengalir per satuan waktu yang arus diperoleh dari beban yang diberikan pada lampu yaitu dengan menggunakan volt ampere meter.

Efisiensi Sistem merupakan perbandingan antara daya listrik yang dihasilkan oleh generator dengan daya yang diberikan oleh air. Pada efisiensi sistem ini menunjukkan kemampuan sistem mengubah energi air menjadi energi listrik. Daya keluaran (Po) yang dihasilkan oleh system turbin angin adalah perkalian daya angin dengan efisiensi system (E). efisiensi system meliputi efisiensi rotor (Er), efisiensi transmisi (Et), dan efisiensi generator (Eg), (Albani dan Ibrahim, 2013):

$\eta_{s}=\frac{P l}{P a i r}$

Dimana daya listrik (watt) dipeoleh dari tegangan (volt) dan arus (ampere) setelah diberikan beban lampu

\section{METODE PENELITIAN}

Metode yang digunakan adalah eksperimental, aliran air mula-mula diukur menggunakan current meter dengan model BFM001. Skema alat penelitian ditunjukan pada gambar 1 dan foto pengujian alat disajikan pada gambar 2. Energi kinetik air selanjutnya akan menggerakkan sudu turbin sehingga berputar. Putaran tersebut kemudian diteruskan ke generator menggunakan system transmisi pulley dan sabuk. Sudu turbin terbuar dari plat galvanis $1 \mathrm{~mm}$ dengan diameter serta tinggi rotor $500 \mathrm{~mm}$. Jumlah sudu yang diuji divariasikan yaitu 2, 3 dan 4 buah sudu. Putaran rotor diukur menggunakan digital tachometer DT-2234C dan besarnya beban pengereman menggunakan timbangan digital. Generator yang digunakan pada penelitian adalah generator AC 3 phase model PMG 165-0.05KW 300 rpm. Arus dan tegangan yang dihasilkan kemudian diukur menggunakan digital multitester model DT-9205A. Pengujian dilakukan dengan dan tanpa konsentrator. Konsentrator ditempatkan tepat di depan sudu turbin yang mengarahkan aliran air ke sudu yang memiliki drag positif. Rasio konsentrator yang digunakan adalah 2, dimana rasio konsentrator merupakan perbandingan luasan masuk terhadap luasan keluar. 


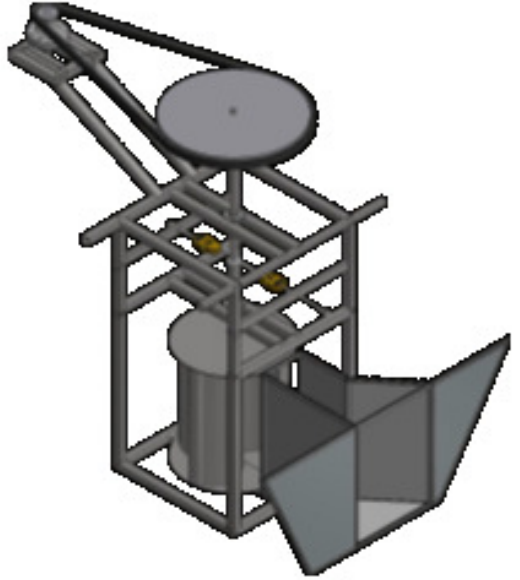

Gambar 2. Skema alat penelitian

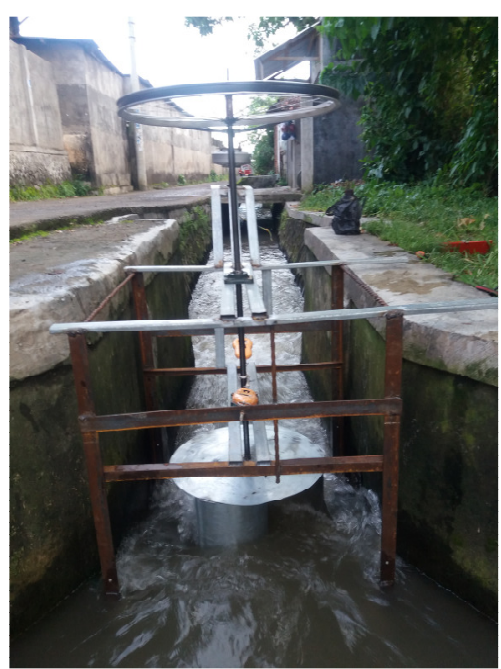

Gambar 3. Pengujian alat

\section{HASIL DAN PEMBAHASAN}

Dalam penelitian ini, coefficient performance atau CP yang dicari pada pengujian meliputi kecepatan air $(\mathrm{m} / \mathrm{s})$, beban pengereman $(\mathrm{kg})$, putaran rotor $(\mathrm{rpm})$, massa jenis $\left(\mathrm{kg} / \mathrm{m}^{3}\right)$, yaitu untuk mendapatkan nilai daya air dan daya rotor. Sedangkan Efisiensi sistem dicari pada pengujian ini meliputi kecepatan air (m/s), arus listrik (ampere) dan tegangan (volt) yaitu untuk mendapatkan daya listrik yang dihasilkan dengan daya air yang dihasilkan

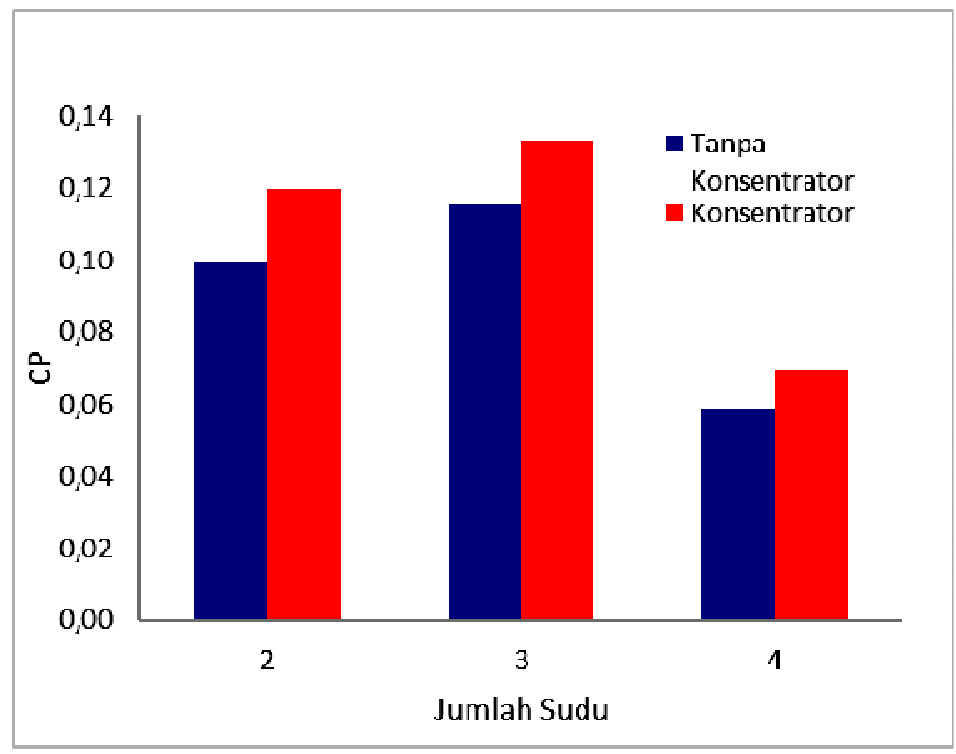

Gambar 4. Pengaruh jumlah sudu terhadap CP

Hubungan jumlah sudu terhadap coefficient performance bahwa dari tiga turbin yang diuji pada turbin Savonius tanpa menggunakan konsentrator, hasil pengujian pada jumlah sudu 2 diperoleh coefficient performance rata-rata sebesar 0,10 , kemudian pada jumlah sudu 3 nilai coefficient performance meningkat menjadi 0,11 , dan pada jumlah sudu 4 coefficient performance menurun menjadi 0,05 . Sedangkan pengujian dengan menggunakan penambahan konsentrator pada gambar 4 
menunjukkan bahwa hasil pengujian pada jumlah sudu 2 diperoleh coefficient performance sebesar 0,12 kemudian coefficient performance pada jumlah sudu 3 meningkat menjadi 0,13 dan pada jumlah sudu 4 diperoleh coefficient performance sebesar 0,07. Jumlah sudu 3 memiliki nilai CP yang paling tinggi, dengan penambahan konsentrator akan meningkatkan nilai CP peningkatan yang diperoleh pada jumlah sudu 2 yaitu sebesar 21,23\% kemudian dengan jumlah sudu 3 meningkat sebesar $15,52 \%$ dan pada jumlah sudu 4 terjadi peningkatan sebesar 18,24\%. Dengan penambahan konsentrator menunjukkan bahwa coefficient performance meningkat bila dibandingkan dengan pengujian tanpa konsentrator. Hal yang serupa juga diperoleh pada penelitian turbin Savonius dengan penambahan konsentrator pada fluida udara, Alit dkk. (2016, 2017). Jumlah sudu yang baik untuk coefficient performance diperoleh pada jumlah sudu 3 kemudian 2 dan terakhir 4 dari tiga jenis turbin yang diuji.

Pengujian turbin dengan penambahan konsentrator secara umum akan meningkatkan $\mathrm{CP}$ turbin, CP yang tinggi terjadi pada pengujian jumlah sudu 3 hal ini disebabkan karena daya rotor, dan daya air. Semakin tinggi nilai daya rotor maka CP pada turbin juga akan meningkat. Secara umum dengan menggunakan penambahan konsentrator memiliki pengaruh terhadap CP pada turbin, konsentrator akan mengarahkan air seperti efek penyempitan pada nozle, karena terdapat perbedaan luas penampang pada konsentrator menyebabkan kecepatan aliran air mengalami perubahan.

hubungan jumlah sudu terhadap daya listrik menunjukkan dari tiga turbin yang diuji bahwa daya listrik pada pengujian tanpa konsentrator dengan menggunakan jumlah sudu 2 diperoleh daya listrik rata-rata sebesar 9,72 watt, kemudian daya listrik rata-rata pada pengujian dengan menggunakan jumlah sudu 3 sebesar 9,79 watt, dan daya listrik rata-rata pada pengujian dengan menggunakan jumlah sudu 4 diperoleh 3,55 watt, seperti ditunjukkan pada gambar 5 .

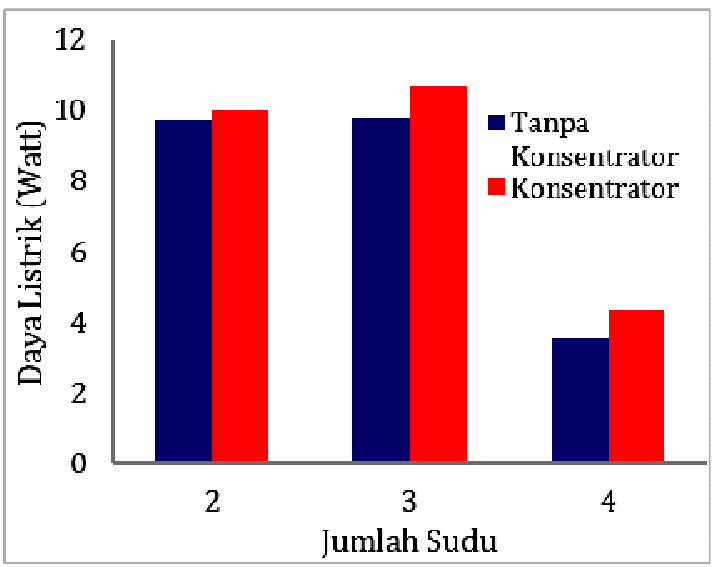

Gambar 5. Pengaruh jumlah sudu terhadap efisiensi sistem

Sedangkan pengujian turbin dengan menggunakan penambahan konsentrator hasil pengujiannya adalah pada jumlah sudu 2 diperoleh daya listrik rata-rata sebesar 9,99 watt, kemudian daya listrik rata-rata pada jumlah sudu 3 meningkat menjadi 10,67 watt dan pada jumlah sudu 4 diperoleh daya listrik rata-rata sebesar 4,33 watt. Hasil ini dikarenakan semakin besar tegangan dan arus listrik maka semakin besar daya listrik yang dihasilkan. Sedangkan pengujian dengan menggunakan penambahan konsentrator, daya listrik meningkat bila dibandingkan dengan pengujian tanpa konsentrator, daya listrik yang tertinggi diperoleh pada turbin dengan jumlah sudu 3 baik turbin tanpa konsentrator maupun turbin dengan penambahan konsentrator, kemudian jumlah sudu 2, dan terakhir jumlah sudu 4, dari tiga turbin yang diuji, secara umum penambahan konsentrator bisa meningkatkan daya listrik.

\section{KESIMPULAN}

Dari hasil penelitian dan perhitungan yang telah dilakukan bisa ditarik kesimpulan sebagai berikut. Koefisien performance pada pengujian turbin tanpa konsentrator maupun dengan konsentrator diperoleh koefisien yang tertinggi pada jumlah sudu 3 yaitu sebesar 0,11 dan 0,13 kemudian jumlah sudu 2 sebesar 0,10 dan 0,12 dan jumlah sudu 4 sebesar 0,05 dan 0,06. Efisiensi sistem pada pengujian turbin tanpa konsentrator maupun dengan konsentrator diperoleh efisiensi sistem yang tertinggi pada jumlah sudu 3 yaitu sebesar $9,83 \%$ dan $11,74 \%$ kemudian jumlah sudu 2 sebesar $8,73 \%$ dan $9,87 \%$ dan 4 sudu dengan efisiensi sistem sebesar $3,91 \%$ dan $4,76 \%$. Dari tiga 
turbin yang telah diuji dengan pengujian tanpa konsentrator maupun dengan menggunakan penambahan konsentrator maka bisa disimpulkan bahwa hasil pengujian yang tinggi terjadi pada jumlah sudu 3, kemudian jumlah 2 dan terakhir jumlah sudu 4.

\section{UCAPAN TERIMAKASIH}

Penulis dalam kesempatan ini mengucakan banyak terimakasih kepada semua pihak yang membantu baik berupa materi maupun pikiran sehingga paper ini dapat terselesaikan. Penulis juga mengucapkan terima kasih pada Jurusan Teknik mesin atas fasilitas yang dipergunakan dalam penelitian ini.

\section{DAFTAR SIMBOL DAN SINGKATAN}

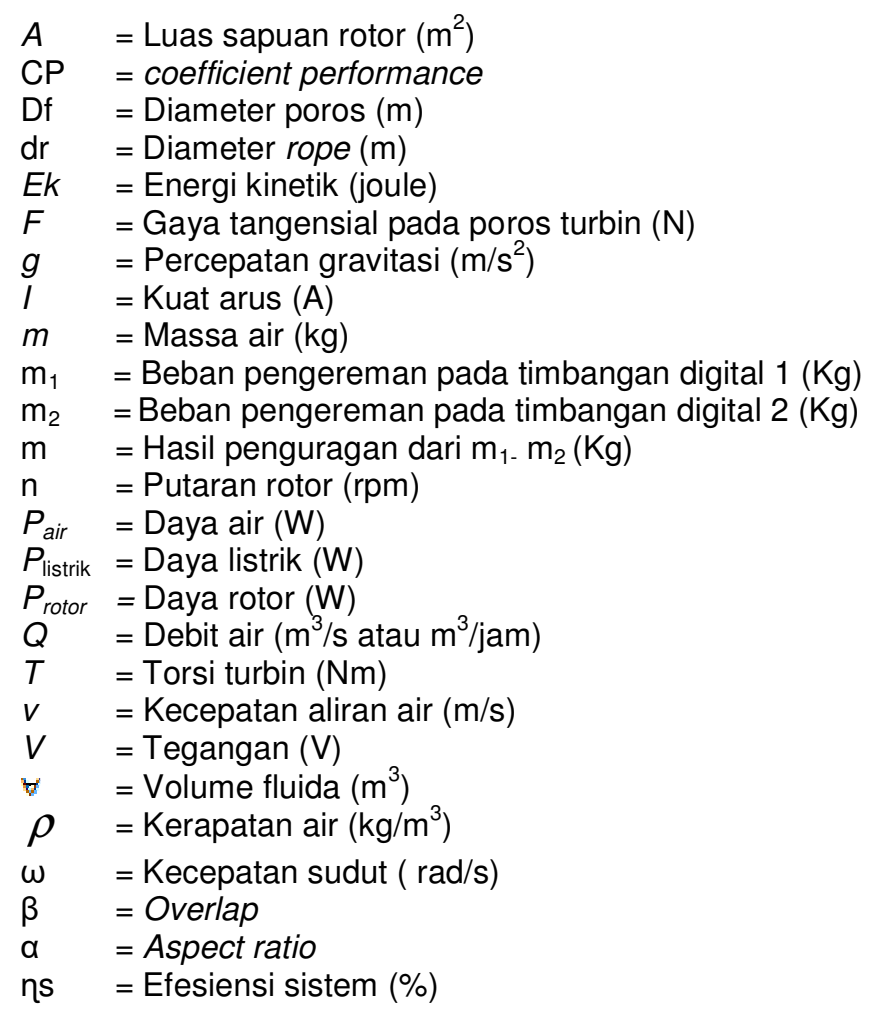

\section{DAFTAR PUSTAKA}

Ali M.A, 2013, Experimental comparison study for Savonius wind turbine of two \& three blades at low wind speed, International Journal Modern Research IJMER, 3(5), 2978-2986.

Alit I.B., Mirmanto, Susana I.G.B., 2018, Experimental performance of a modified Savonius turbine for small scale portable wind power generation, International Journal of Mechanical Engineering and Technology (IJMET), 9(6), 1166-1173.

Alit I.B., Sutanto, R., Mara I.M., Mirmanto, 2017, Effect of concentrator, blade diameter and blade number on the Savonius wind turbine performance, Asian Journal of Applied Sciences, 5(2), 343351.

Alit I.B., Nurchayati, Pamuji S.H., 2016, Turbin angin poros vertikal tipe Savonius bertingkat dengan variasi posisi sudut, Dinamika Teknik Mesin, 6, 107-112.

Albani A., Ibrahim M.Z., 2013, Preliminary development of prototype of Savonius wind turbine for application in low wind speed in Kuala Terengganu, Malaysia, International Journal of Scientific \& Technology Research, 2(3), 102-108.

Balineni S.R., Kumar K.B.S, Kumar G.V., 2011, Design and fabrication of Savonius vertical axis wind turbin, Department of Mechanical Engineering Gokaraju Rangaraju Institute of Engineering and Technology, Jawaharlal Nehru Technological University.

Golecha K., Eldho T.I., Prabhu S.V. 2012, Performance study of modified Savonius water turbine with two deflector plates, International Journal of Rotating Machinery. 
Mahmoud N.H., Haroun A.A., Wahba E., Nasef M.H., 2012, An experimental study on improvement of Savonius rotor performance, Alexandria Engineering Journal, 51, 19-25.

Purnama A.C., Hantoro R., Nugroho G., 2013, Rancang bangun turbin air sungai poros vertikal tipe Savonius dengan menggunakan pemandu arah aliran, Jurnal Teknik POMITS, 2(2), 278-282. 